\title{
2-Aminothiazole-Derived Opiates -Bioisosteric Replacement of Phenols
}

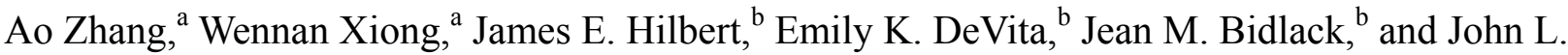

Neumeyer ${ }^{\mathrm{a}, *}$

${ }^{a}$ Alcohol and Drug Abuse Research Center, McLean Hospital, Harvard Medical School, 115 Mill Street, Belmont, MA 02478, USA

${ }^{b}$ Department of Pharmacology and Physiology, School of Medicine and Dentistry, University of Rochester, Rochester, NY 14642, USA
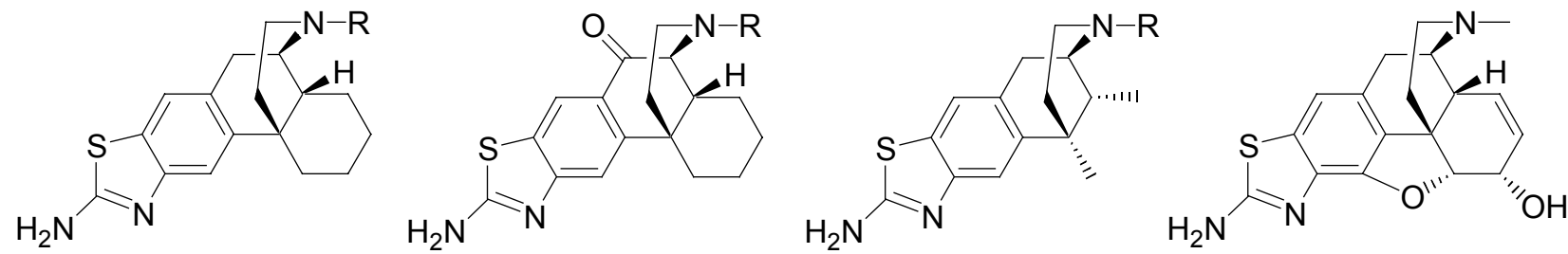

$$
\mathrm{R}=: \mathrm{Me} \text {, }
$$<smiles>CCC1CC1CC1CCC1</smiles>

${ }^{*}$ To whom correspondence should be addressed. Tel: 617-855-3388; Fax: 617-855-2519; Email: Neumeyer@mclean.harvard.edu 